\title{
SISTEM PENGENDALIAN SUHU DAN PEMANTAUAN KELEMBABAN BIJI KOPI PADA MESIN PENYANGRAI BERBASIS ARDUINO 2560
}

\author{
Anggi Permana, Iman Setiono \\ Program Studi Diploma III Teknik Elektro \\ Sekolah Vokasi, Univeritas Diponegoro
}

\begin{abstract}
Anggi Permana, Iman Setiono, in this paper explain that along with the development of modern times. Technological advancements were increasingly found in manufacturing products, everything was done to be easy and practical. These products are made with the aim of helping human work. However, not all manufacturing products are automated. Some products still work manually. Therefore, we are required to be able to innovate by changing the manual process with a more efficient method by using products that are automatic. One tool is the roasting machine for coffee beans. Currently on the market it is rare for automatic coffee roasters to be designed. Most coffee roasters are done manually, use hand mixers, and use wood stoves or gas stoves. This situation becomes less efficient where the roasting is still using the hands, causing it to ripen evenly and burn. Though to get the right coffee is from the roasting process. Roasting determines the color and variety of flavors of coffee to be consumed. The effect of temperature and time also affects the results of roasting, even when roasting here we monitor the thickness of coffee beans. to produce good roasting. The principle is to give the right amount of time and the right temperature so that coffee will not only have a fragrant aroma but also create the right taste. To solve the problem, in this article we made coffee bean roasters. This coffee bean roasting system is based on Arduino MEGA type 2560. The roasting process uses the mlx90614 sensor and DHT11 sensor to monitor the moisture of coffee beans that will be displayed on the 7-segment. The heating media used is using heat elements instead of stoves. This tool is able to roast as much as 400 grams of coffee. It is expected that the roasting machine of coffee beans will be more optimal
\end{abstract}

Keywords: Arduino MEGA, heat element, DHT11 sensor, MLX90614 sensor and, 7-segment.

\section{PENDAHULUAN}

Kopi mempunyai citra rasa yang unik. Walaupun biji sama, asalnya sama namun rasa bisa berbeda. Kenapa demikian?. Karena proses pengelolahan dari kopi itu sendiri yang dapat menyebabkan rasa kopi itu berbeda. Salah satu proses nya yaitu sangrai kopi (roaster coffee) yang sangat menentekuan rasa dan wangi kopi. Menyangrai kopi dengan cara yang benar oleh penyangrai ahli akan menghasilkan kopi bubuk berkualitas tinggi yang ditandai dengan rasa yang gurih dan wangi yang harum.

Prinsip roaster coffe yaitu temperatur yang pas dan lama yang tepat. Biji yang disangrai lama pada temperatur rendah akan menyebabkan minyak dan senyawa-senyawa kimia penting terbang sehingga kopi terasa hambar. Biji yang disangrai singkat pada temperatur tinggi akan menyebabkan biji tidak matang merata, artinya kulit luar terlihat matang tapi bahagian dalam tidak matang. Lama sangrai dan temperatur disesuaikan terhadap hasil akhir yang akan dicapai.

Dari permasalahan tersebut mendorong penulis untuk membuat sebuah terobosan yang dapat digunakan untuk mengontrol dan memonitoring. Alat tersebut adalah suatu alat yang dirancang untuk mempermudah manusia dalam menyangrai biji kopi otomatis ini dilengkapi dengan komponen Arduino Mega, Sensor MLX90614 dan Sensor DHT11. Dimana Sistem kontrol pada rangkaian ini menggunakan Arduino Mega berfungsi untuk mengatur proses kerja dari Sensor MLX90614 dalam mengontrol suhu pada saat proses penyangraian biji kopi. Sehingga Sensor MLX90614 dapat menginstruksikan elemen panas bekerja pada alat Roaster coffee. Sedangkan Sensor DHT11 berfungsi untuk memonitoring kelembapan biji kopi saat disangrai.

\section{Elemen Pemanas}

Elemen pemanas merupakan sebuah transduser yang dapat mengubah energi listrik menjadi energi panas melalui proses Joule Heating. Elemen pemanas terbuat dari bahan material konduktor yang dapat menghantarkan panas secara konveksi, konduksi maupun radiasi. Secara karakteristik fisik dan kimia dari bahan elemen pemanas menentukan kualitas panas yang dihasilkan oleh elemen pemanas, karena material penghasil panas menjadi faktor utama yang menentukan proses perpindahan panas dari material elemen pemanas ke material yang dipanaskan. Gambar elemen pemanas ditunjukkan pada gambar 1 .

Persyaratan elemen pemanas antara lain:

- Harus tahan lama pada suhu yang dikehendaki.

- Sifat mekanisnya harus kuat pada suhu yang dikehendaki.

- Koefisien muai harus kecil, sehingga perubahan bentuknya pada suhu yang dikehendaki tidak terlalu besar.

- Tahanan jenisnya harus tinggi. 
- Koefisien suhunya harus kecil, sehingga arus kerjanya sedapat mungkin konstan

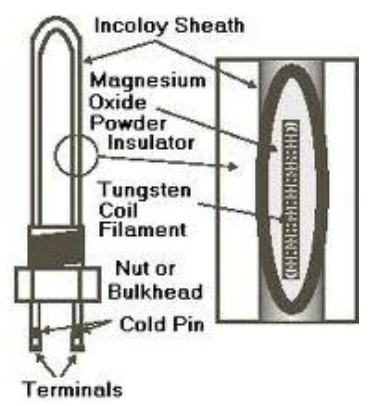

Gambar 1. Elemen pemanas

\section{CARA KERJA SECARA KESELURUHAN}

Gambar rangkaian keseluruhan sistem ini dapat dilihat pada gambar 2 .

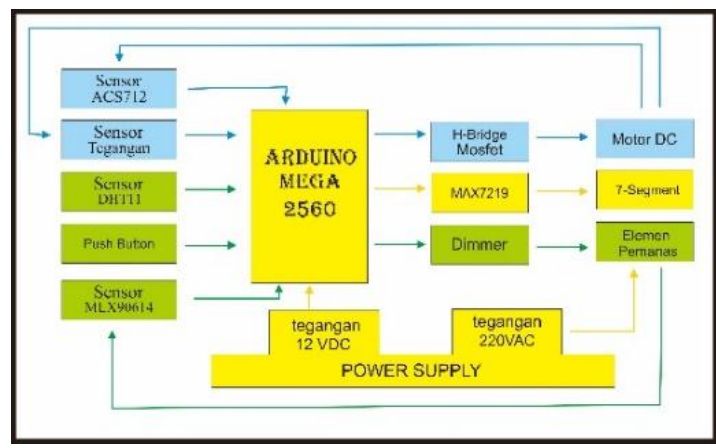

Gambar 2. Rangkaian Diagram Blok Keseluruhan Dari Sistem Rangkaian

\section{Rangkaian MLX90614}

MLX90614 adalah termometer inframerah yang dirancang untuk penginderaan suhu nonkontak. Sensor memberikan pembacaan suhu ratarata dari semua objek yang tercover oleh view dari sensor. ADC 17-bit internal dan DSP yang kuat berkontribusi pada akurasi dan resolusi MLX90614 yang tinggi. Ini memiliki sejumlah besar aplikasi termasuk pengukuran suhu tubuh dan deteksi gerakan.

Dengan menggunakan sensor ini, kita dapat mengukur temperatur dari -95 dan $720^{\circ} \mathrm{F}$ (-70 sampai $382,2^{\circ} \mathrm{C}$ ) dengan resolusi sampai 17 bit. Hal ini artinya, sama dengan $128 \mathrm{X}$ lebih cepat dari kemampuan $\mathrm{ADC}$ arduino dan dapat memiliki arti dapat membedakan antara $25^{\circ} \mathrm{C}$ dan $25.02^{\circ} \mathrm{C}$ tanpa melakukan kontak dengan objek. Dengan data sampai 17 bit, maka kita akan mendapatkan resolusi sampai $0.0034^{\circ} \mathrm{C}$. Bentuk fisik dari modul MLX90614 ditunjukkan pada gambar 3, sedangkan gambar 4 menunjukkan gambar rangkaian dari MLX90614.

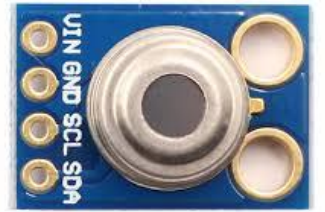

Gambar 3. MLX90614

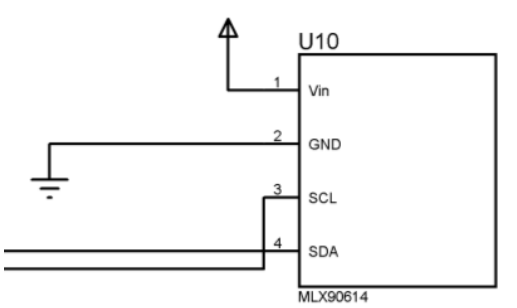

Gambar 4. Rangkaian MLX90614

\section{Rangkaian DHT11}

DHT11 adalah sensor digital yang dapat mengukur suhu dan kelembaban udara di sekitarnya. Sensor ini sangat mudah digunakan bersama dengan Arduino. Memiliki tingkat stabilitas yang sangat baik serta fitur kalibrasi yang sangat akurat. Koefisien kalibrasi disimpan dalam OTP program memory, sehingga ketika internal sensor mendeteksi sesuatu, maka module ini menyertakan koefisien tersebut dalam kalkulasinya,DHT11 ini termasuk sensor yang memiliki kualitas terbaik, dinilai dari respon, pembacaan data yang cepat, dan kemampuan anti-interference. Ukurannya yang kecil, dan dengan transmisi sinyal hingga 20 meter,dengan sepsifikasi: Supply Voltage: $+5 \mathrm{~V}$, Temperature range : 0-50 ${ }^{\circ} \mathrm{C}$ error of $\pm 2{ }^{\circ} \mathrm{C}$, Humidity : $20-90 \% \mathrm{RH} \pm 5 \%$ $\mathrm{RH}$ error,dengan sesifikasi digital interfacing system. membuat produk ini cocok digunakan untuk banyak aplikasi-aplikasi pengukuran suhu dan kelembaban. Rangkain DHT11 ditunjukkan pada gambar 5 .

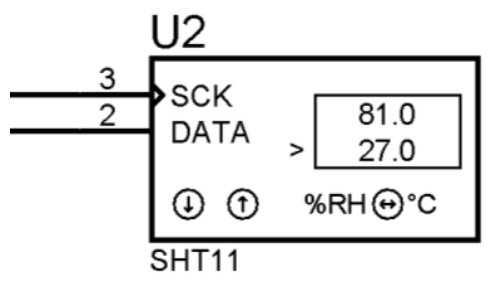

Gambar 5. Rangkaian DHT11

\section{Rangkaian seven segment}

Rangkaian 7 segment merupakan rangkaian keseluruhan sistem yang digunakan sebagai display atau tampilan. Masing masing tampilan 3 digit angka, rangkaian ini akan menampilkan status suhu, timer dan kelembaban. 7 segment dihubungkan melalui max7129 sebelum ke arduino. Gambar 6 memperlihatkan rangkaian seven segment. 


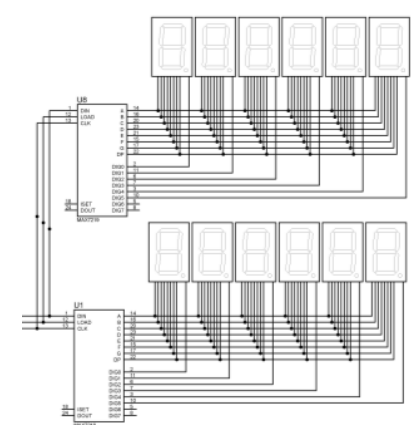

Gambar 6. Rangkaian seven segment

\section{Rangkaian Dimmer}

Rangkaian Dimmer dalam sistem ini digunakan sebagai alat penghubung antara Arduino Mega 2560 dengan beban. Beban disini menggunakan tegangan AC. Tegangan AC digunakan untuk menghidupkan pemanas. Sistem kontrol yang digunakan yaitu kontrol tegangan AC secara sudut fasa dengan triac. Sumber tegangan AC yang terhubung dengan triac digunakan untuk mengatur daya yang diberikan pada pemanas sesuai besar suhu yang terbaca oleh sensor MLX90614. Rangkaian Dimmer ini berfungsi untuk mempertahankan tegangan yang di inginkan agar tetap stabil. Rangkaian Dimmer dapat dilihat pada gambar 7.

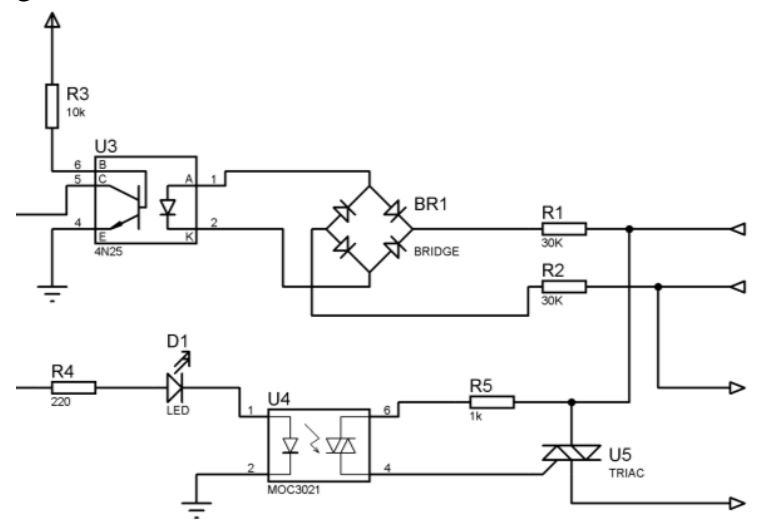

Gambar 7. Rangkaian Dimmer

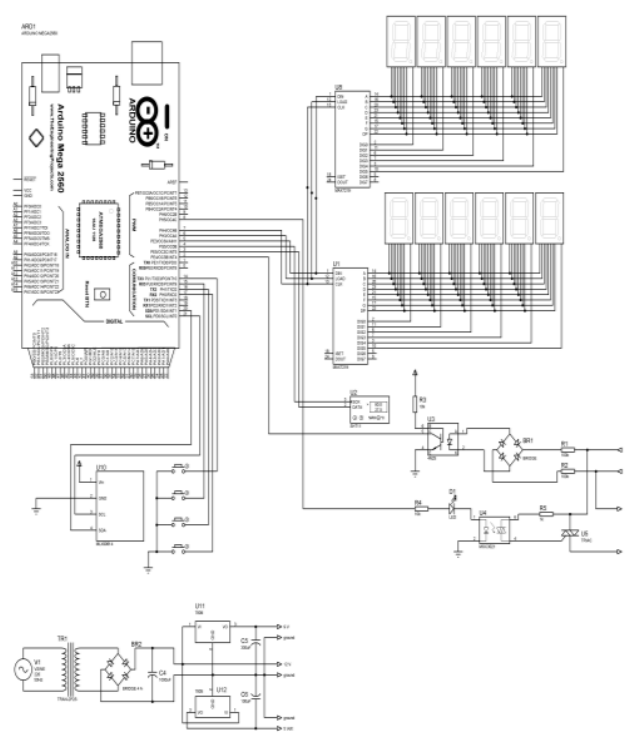

Gambar 8. Rangkaian keseluruhan

Gambar rangkaian keseluruhan ditampilkan pada gambar 8 . Mesin penyangrai ini menggunakan MLX90614, untuk mendeteksi suhu pada tabung pemanas yang di kontrol dengan push button dan DHT11 untuk mendeteksi kelembaban yang di tampilkan pada seven segment sehingga dapat dipantau saat sedang menyangrai kopi. Mesin penyangrai ini juga menggunakan push button untuk mengatur suhu dan waktu penyangraian.

Mikrokontroller Arduino Mega 2560 yang telah diberi program serta inputan tegangan $12 \mathrm{~V}$, akan memberikan perintah pada MLX90614 untuk pembacaan suhu yang sesuai dengan suhu yang di set dengan push button selanjutnya elemen pemanas akan bekerja yang dikendalikan oleh rangkaian dimmer.

Setelah proses penyangraian selasai sistem akan berhenti dengan sendirinya.

\section{PENGUJIAN DAN ANALISIS}

Pengukuran dan pengujian dilakukan pada masing-masing rangkaian. Hal itu bertujuan untuk mengetahui kemungkinan adanya kesalahan pada rangkaian. Serta untuk mengetahui nilai besaran listrik keluarannya. Gambar 9 menunjukkan titiktitik pengukuran untuk rangkaian catu daya dan hasilnya diperlihatkan pada tabel 1 .

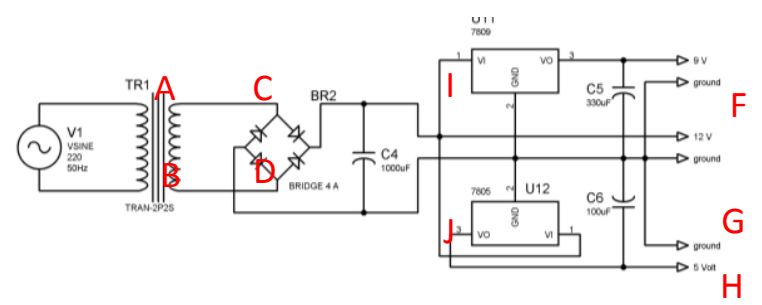

Gambar 9. Pengukuran Rangkaian catu daya 
Tabel 1. Data hasil Pengukuran Rangkaian catu daya

\begin{tabular}{|c|c|c|c|}
\hline No & $\begin{array}{l}\text { Bagian } \\
\text { yang } \\
\text { diukur }\end{array}$ & $\begin{array}{l}\text { Titik } \\
\text { Pengukuran }\end{array}$ & Tegangan (V) \\
\hline 1 & $\begin{array}{l}\text { Input } \\
\text { Trafo }\end{array}$ & A-B & 220 \\
\hline 2 & $\begin{array}{l}\text { Output } \\
\text { Trafo }\end{array}$ & C-D & 12.6 \\
\hline 3 & $\begin{array}{l}\text { Output } \\
\text { IC } 7809\end{array}$ & E-F & 9.18 \\
\hline 4 & $\begin{array}{l}\text { Output } \\
\text { IC } 7805\end{array}$ & G-H & 4.99 \\
\hline 5 & $\begin{array}{l}\text { Output } \\
\text { diode } \\
\text { bridge }\end{array}$ & I-J & 15.6 \\
\hline
\end{tabular}

Titik-titik pengukuran untuk rangkaian dimmer ditunjukkan pada gambar 10 dan hasilnya disajikan pada tabel 2 .

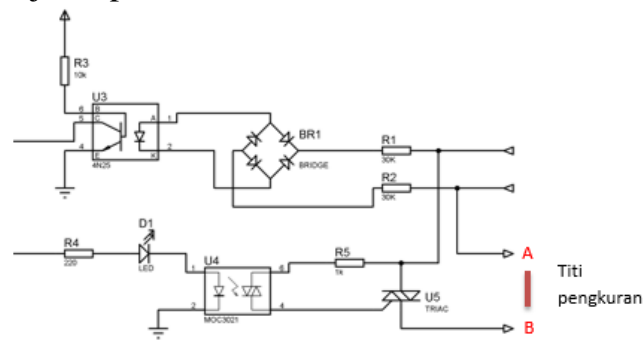

Gambar 10. pengukuran rangkaian dimmer

Tabel 2. data hasil pengukuran

\begin{tabular}{llll}
\hline No & PWM & $\begin{array}{l}\text { Tegangan } \\
(\mathbf{V})\end{array}$ & Duty Cycle \% \\
\hline 1 & 50 & 30 & 19.6 \\
2 & 100 & 100.7 & 39.21 \\
3 & 150 & 164.7 & 58.82 \\
4 & 200 & 208.9 & 78.43 \\
5 & 255 & 219.5 & 100 \\
\hline
\end{tabular}

Untuk rangkaian sensor suhu, titik pengukuran ditunjukkan pada gambar 11 dan hasilnya diperlihatkan pada tabel 3 .

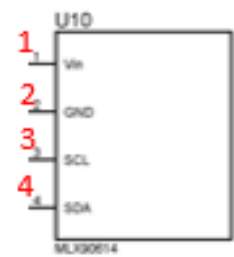

Gambar 11. Pin pin sensor suhu

Tabel 3. hasil pengukuran pin sensor

\begin{tabular}{ccc}
\hline $\begin{array}{c}\text { Kaki } \\
\text { nomor }\end{array}$ & Nama Pin & Tegangan V \\
\hline 1 & Vin & 3.4 \\
2 & GND & 0 \\
3 dan 4 & SCL dan & 3 \\
& SDA & \\
\hline
\end{tabular}

Untuk hasil percobaan pemanas dan sangria ditunjukkan pada tabel 4 dan 5 .

Tabel 4. Data Hasil percobaan pemanas

\begin{tabular}{ccc}
\hline No & Suhu ${ }^{\mathbf{0}} \mathbf{C}$ & Waktu (detik) \\
\hline 1 & 60 & 121 \\
2 & 70 & 154 \\
3 & 80 & 200 \\
4 & 90 & 245 \\
5 & 100 & 297 \\
\hline
\end{tabular}

\begin{tabular}{ccccc}
\multicolumn{5}{c}{ Tabel 5. Data Hasil percobaan sangrai } \\
\hline $\begin{array}{ccccc}\text { No } & \text { Jumlah } \\
\text { Kopi }\end{array}$ & $\begin{array}{c}\text { Suhu } \\
\mathbf{0} \text { C }\end{array}$ & $\begin{array}{c}\text { Waktu } \\
\text { (detik) }\end{array}$ & Ket. \\
\hline 1 & 100 gr & 100 & 7 & Belum matang \\
& & & 10 & $\begin{array}{c}\text { Coklat muda } \\
\text { belum matang } \\
\end{array}$ \\
& & & 13 & Matang light \\
& & & 15 & Matang french \\
2 & $200 g r$ & 100 & 11 & Belum matang \\
& & & 15 & Coklat muda \\
& & & & belum matang \\
& & & 27 & Matang light \\
& & & 36 & Matang french \\
3 & $300 g r$ & 100 & 15 & Belum matang \\
& & & 32 & Coklat muda \\
& & & & belum matang \\
& & & 50 & Matang light \\
& & & 61 & Matang french \\
\hline
\end{tabular}

\section{KESIMPULAN}

Kesimpulan yang diperoleh dari penelitian ini adalah sebagai berikut :

- Sensor suhu MLX90614 dapat mendeteksi suhu yang dihasilkan pada objek dengan memanfaatkan gelombang inframerah sehingga tidak memerlukan kontak antara objek dan sensor.

- Jumlah kopi dan suhu sangat berpengaruh selama penyangraian

- Arduino Mega 2560 digunakan sebagai pengolah data inputan dari sensor suhu MLX90614 yang kemudian ditampilkan di 7 segment.

- 7segment pada alat ini digunakan untuk menampilkan suhu, kelembaban, dan waktu dari mesin penyangrai.

- Mesin penyangrai ini dapat digunakan para penggemar kopi yang ingin menyangrai sendiri.

\section{DAFTAR PUSTAKA}

1. Musbikhin. 2011. Penegertian sensor dan macam-macam sensor. (http://www.musbikhin.com/pengertian-sensordan-macam-macam-sensor). diakses tanggal 4 juni 2017

2. Ardy, faisal. 2016. Pengertian DHT11. (https://docslide.net/documents/2012-2-00944sk-bab2001pdf.html). diakses tanggal 4 juni 2017. 
3. Elok, Dhinda. 2016. Aplikasi Arduino Untuk Monitoring Dan Setting Suhu Piringan Logam Dengan Sensor MLX90614 Pada Aplikasi Pemanas Roti. Tugas Akhir. Tidak diterbitkan. PSD III Teknik Elektro Universitas Diponegoro, Semarang.

4. Ecadio. 2017. Teori arduino. (http://ecadio.com/belajar-dan-mengenalarduino-mega). diakses tanggal 30 april 2017.

5. Syahwil, muhammad. 2017. Panduan Mudah Balajar Arduino Menggunakan Simulasi Proteus. Andi Offset. jakarta

6. Kho, Dickson. 2017. Pengertian 7segment. (http://teknikelektronika.com/pengertian-sevensegment-display-layar-tujuh-segmen/). diakses tanggal 2 mei 2017.

7. Permata, Redi. (2016). Rancang Bangun Sistem Pengontrol BATCH MIXER Pada Industri Minuman Dengan Metode PID Berbasis Arduino Uno R3. Tugas Akhir. Tidak diterbitkan. PSD III Teknik Elektro Universitas Diponegoro, Semarang.

8. Restiawan, Masde. (2016). Otomatisasi Pengatur Suhu Dan Waktu Pada Penyangrai Kopi ( Roaster Coffee ) Berbasis Atmega 16 Pada Tampilan Led ( Liquid Crystal Display). Tugas Akhir. Tidak diterbitkan. PSD III Teknik Elektro Universitas Diponegoro, Semarang. 